\title{
Dermaseptins and Magainins: Antimicrobial Peptides from Frogs' Skin-New Sources for a Promising Spermicides Microbicides-A Mini Review
}

\author{
Amira Zairi, ${ }^{1}$ Frédéric Tangy, ${ }^{2}$ Khaireddine Bouassida, ${ }^{1}$ and Khaled Hani ${ }^{1}$ \\ ${ }^{1}$ Laboratory of Biochemistry, Faculty of Medicine, 4002 Sousse, Tunisia \\ ${ }^{2}$ Institut Pasteur, Unité des virus lents, CNRS URA 1930, 75015 Paris, France \\ Correspondence should be addressed to Khaled Hani, hani.k@planet.tn
}

Received 4 December 2008; Accepted 17 August 2009

Recommended by Lori Snyder

Sexually transmitted infections (STIs) and human immunodeficiency virus (HIV), the causative agents of acquired immunodeficiency syndrome (AIDS), are two great concerns in the reproductive health of women. Thus, the challenge is to find products with a double activity, on the one hand having antimicrobial/antiviral properties with a role in the reduction of STI, and on the other hand having spermicidal action to be used as a contraceptive. In the absence of an effective microbicide along with the disadvantages of the most commonly used spermicidal contraceptive worldwide, nonoxynol-9, new emphasis has been focused on the development of more potential intravaginal microbicidal agents. Topical microbicides spermicides would ideally provide a female-controlled method of self-protection against HIV as well as preventing pregnancies. Nonoxynol-9, the only recommended microbicide spermicide, damages cervicovaginal epithelium because of its membrane-disruptive properties. Clearly, there is an urgent need to identify new compounds with dual potential microbicidal properties; antimicrobial peptides should be candidates for such investigations. Dermaseptins and magainins are two classes of cationic, amphipathic $\alpha$-helical peptides that have been identified in the skin extracts of frogs Phyllomedusa sauvagei and Xenopus laevis. Regarding their contraceptive activities and their effect against various STI-causing pathogens, we believe that these two peptides are appropriate candidates in the evaluation of newer and safer microbicides spermicides in the future.

Copyright ( 2009 Amira Zairi et al. This is an open access article distributed under the Creative Commons Attribution License, which permits unrestricted use, distribution, and reproduction in any medium, provided the original work is properly cited.

\section{Introduction}

The human immunodeficiency virus/the causative agent of acquired immunodeficiency syndrome (HIV/AIDS) pandemic continues its spread at a rate of over 15000 new infections every day. Sexual transmission of HIV-1 is the dominant mode of this pandemic spread. For the first time since the disease emerged in the early 1980s, about half the 42 million people now living with HIV/AIDS worldwide are women. Worldwide, more than 90 percent of all adolescent and adult HIV infections have resulted from heterosexual intercourse [1]. Therefore, effective strategies are needed to reduce heterosexual and prenatal HIV transmission. In the absence of an efficient prophylactic anti-HIV therapy or vaccine, recent emphasis has been placed on the development of intravaginal microbicidal agents capable of reducing the transmission of HIV [2]. In addition, prophylactic contraception is fundamentally important for HIV infected women to prevent pregnancy and HIV transmission, especially because $80 \%$ of women with AIDS are childbearing age. So, unwanted pregnancy is another major concern for sexually active women [2]. Worldwide, at least half of all pregnancies, an estimated 133 million annually, are unintended [3].

As most of the new sexually transmitted infections (STIs) and HIV infections are the result of unprotected heterosexual intercourse, the use of barrier contraceptives like condoms was an alternative, which aimed at controlling the spread of these infections [3]. Studies support the fact that the correct and consistent use of condoms protect men and women from HIV infection and other STIs [4]. However, drawbacks associated with such barrier methods, like men being reluctant to use condoms and women being unable to negotiate their use, have forced the search for better and 
more acceptable alternatives. One such area that is being extensively explored is the microbicides.

Microbicides are antimicrobial products and formulations. They are intended for self-administration before sexual intercourse to protect against the transmission of HIV and other sexually transmitted infection-causing microbes. Microbicides can be used by women without negotiation with their partners. This is an important characteristic because condom-dependant protection has been unsuccessful in halting the spread of HIV and other sexually transmitted infections. The world population continues its steep rise, leading to serious overpopulation problem in certain regions [5]. Consumer preference studies suggest that most women worldwide prefer a vaginal prophylactic product with both antimicrobial and contraceptive effects [5].

At the present time, hundreds of spermicidal products have been marketed. Most of them contain a detergent as an active ingredient, such as nonoxynol-9 (N-9), and benzalkonium chlorides. Some of these detergents have also exhibited microbicidal activity in vitro $[6,7]$.

The spermicidal activities of these surfactants are associated with their structural affinity to the lipid membranes [8]. However, numerous laboratory studies have now shown that detergent spermicides do not provide any protection against STD, and their effect in preventing human immunodeficiency virus (HIV) transmission remains controversial [9]. The major drawback of using N-9 or other currently used surfactants is their detergent-like action on epithelial cells and normal vaginal flora $[10,11]$. The repeated use of a surfactant as a vaginal contraceptive/microbicide has been associated with an increased risk of vaginal or cervical infection and irritation or ulceration [11-13], detergenttype spermicides alter vaginal bacterial flora, and such disturbance of the vaginal microbial milieu can lead to opportunistic infections [10], which in turn increases the chance of HIV/STI transmission.

Due to this effect, it is important to identify and evaluate a new generation of products with dual activity as antimicrobial/antiviral agents to reduce STIs and as spermicidal agents for contraception. Innovative and promising sources of candidate molecules are a group of natural components called AMPs.

Antimicrobial peptides are an important component of the natural defences of most living organisms against invading pathogens. These are relatively small $(<10 \mathrm{kDa})$, cationic and amphipathic peptides of variable length, sequence and structure [14-16]. During the past two decades several AMPs have been isolated from species of all kingdoms from insects to plants to mammals and nonmammalian vertebrates as well as from bacteria and fungi. Most of these peptides are obtained from different sources like macrophages, neutrophils, epithelial cells, haemocytes, fat body, reproductive tract, and so forth. These peptides exhibit broad-spectrum activity against bacteria, fungi, eukaryotic parasites and/or viruses [17].

Few studies have concentrated on the action of AMPs on sexually transmitted pathogens. The human-defensins 13 have been shown to contribute to the anti-HIV-1 activity
TABLE 1: Sequences of dermaseptin DS4 and its derivatives.

\begin{tabular}{|c|c|}
\hline Peptide $^{\mathrm{a}}$ & Sequence amino acid ${ }^{\mathrm{b}}$ \\
\hline S4 & ALWMTLLKKVLKAAAKAALNAVLVGANA \\
\hline S4a & - \\
\hline K4S4( 1-28) & $-\ldots \mathrm{K}_{-}-\ldots-\ldots-\ldots-\ldots-\ldots-\ldots$ \\
\hline K4S4 (1-16)a & $\ldots \mathrm{K}_{-\ldots} \ldots \ldots \ldots \mathrm{NH} 2$ \\
\hline S4 (6-28) & 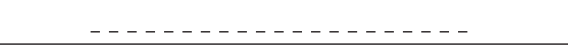 \\
\hline
\end{tabular}

of $\mathrm{CD}^{8}$ antiviral factor secreted by the $\mathrm{CD} 8 \mathrm{~T}$ cells in the HIV infected long term precursors [18]. The activity of protegrins against Neisseria gonorrhoeae has been studied. Protegrins PG-1, $-2,-3$, and -5 are highly active against the pathogen at low micromolar concentrations [19]. The peptides exhibit activity against serum-resistant, serumsensitive and antibiotic-resistant strains. Yasin et al. [20] have demonstrated the susceptibility of Chlamydia trachomatis to protegrins and defensins; while defensins are inactivated in the presence of serum, protegrins retain their activity. A list of peptides showing activity against STI causing pathogens is summarized in Table 1 [14].

Apart from antimicrobial activities, few peptides have been explored for their contraceptive potential. Subtilosin, a bacteriocin produced by Bacillus subtilis, was shown to eliminate the motility and forward progression of human spermatozoa in a dose-dependent manner. Studies have reported that this antimicrobial peptide has proven antimicrobial activity only against Gardenella vaginalis [21]. Reddy et al. were the first to report the contraceptive efficacy of nisin both in vitro and in vivo. Nisin showed a time and dose dependent effect on sperm motility with limited activity against STI causing pathogens [22]. Interestingly, peptides found in the skin secretions of frogs, such as dermaseptins and magainins, posses a potent spermicidal activity against human sperm along with their large spectrum of action against sexually transmitted pathogens [23-27]. This review aims to show that these two peptides are new sources for a promising spermicides microbicides basing on their biological properties.

\section{Antimicrobial Peptides from Frog's Skin: Structure and Mechanism of Action}

Genomes have evolved the capacity to respond to environmental challenges with the highly focused genetic changes [28]. The dermal glands of anuran frogs not only produce huge amounts of biologically active peptides that are very similar to mammalian neuropeptides as hormones [29], but they also contain a rich arsenal of broad spectrum, cytosolic antimicrobial peptides [30]. Many of these peptides exhibit antibiotic, fungicidal, virucidal and tumoricidal activities with a low cytotoxicity towards mammalian cells. These peptides are synthesized as prepropeptides that are processed by the removal of the signal peptide to proform and they are stored in the large granules of the glands [31]. Glands 
may release their peptide content onto the skin surface by holocrine mechanism to provide an effective and fast-acting defense against noxious microorganisms [31]. The antimicrobial peptides are small, 10-50 amino acid residues long, cationic and act in a variety of ways, however permeabilizing and disrupting the target cell membrane is the most frequent mechanism. According to the Shai-Matsuzaki-Huang model, these peptides first bind to the membrane surface up to a critical concentration and then penetrate the membrane's interior [14]. This causes a decrease in the bilayer thickness resulting in disordering the lipid chain, transient pore formation and eventual collapse of the membrane. The physical nature of this mechanism prevents a target organism from developing resistance to the peptide. Hence, these peptides have been recognized as potential therapeutic agents $[32,33]$.

The sequences of these antimicrobial peptides differ considerably from one amphibian to another. The skin of a frog may have 10-20 antimicrobial peptides with different size, sequences, charges, hydrophobicity, tridimensional structures and spectrum of action, and this armament differs between frogs belonging to different families, genera, species or even subspecies, consequently, no two species with the same panoply of peptide antibiotics have yet been found [33].

This impressive divergence between and within species means that there may be as many as 100000 different peptides produced by the dermatous glands of the 5000 anuran amphibians [34]. The striking variations in the peptide sequence of frog skin antimicrobial peptides may be exploited for discovering new molecules and structural motifs targeting specific microorganisms for which therapeutic armamentarium is scarce. In this review, we chose to focus on two peptides of representative amphipathic $\alpha$-helical antimicrobial peptides, namely magainins and dermaseptins. Many studies have shown that these peptides are active against various STI-causing pathogens and HIV/herpes simplex virus both in vitro and in vivo in addition to their contraceptive efficacies. Many other peptides from amphibian skin provide a rich source of broad-spectrum antimicrobial peptides including some that have antiviral activity against HIV such as caerin and maculatin [35]. However the spermicidal activity of these compounds has not been evaluated and no data have shown their contraceptive effect. Comparatively, dermaseptins and magainins with their antimicrobial and spermicidal properties may certainly be beneficial as a safe vaginal contraceptive agent for the control of STIs/HIV infections.

\section{Dermaseptins and Magainins as Microbicides}

Based on the above observations that antimicrobial peptides from frogs attack only the bacterial membranes and have minimal interaction with the mammalian cell membranes, the potentialities of using these molecules as an alternative to the existing detergent-based microbicides can be seriously considered. Various peptides are being explored for their anti-STI and anti-HIV effect. In this review we chose to focus on two peptides of representative amphipathic $\alpha$-helical antimicrobial peptides from frog skin namely magainins and dermaseptins $\mathrm{S}$.

\section{Magainins}

Magainins, also known as PGS (peptide glycine serine) [36], are 23 amino acid long peptides isolated from the skin of the African clawed frog Xenopus laevis [37]. Magainins belong to a large family of amphibian amphipathic $\alpha$-helical antimicrobial peptides. These peptides have been reported to have a wide spectrum of antimicrobial activities against Gram-positive and Gram-negative bacteria and fungi. They are also known to facilitate wound closure and reduce inflammation [38]. Analogs of the peptide demonstrating increased antimicrobial activity have been synthesized [37]. Arhana et al. showed that magainin-A inhibits the growth of various strains of STI-causing pathogens, and the effects were found to be dose-dependant. The calculated MICs for standard strains of Escherichia coli, Staphylococcus aureus, Candida albicans and Pseudomonas aeroginosa were ranging from $50 \mu \mathrm{g} / \mathrm{mL}$ to $150 \mu \mathrm{g} / \mathrm{mL}$. It is worth noting that this peptide did not cause red blood cells (RBC) hemolysis up to $300 \mu \mathrm{g} / \mathrm{mL}$ [39]. The antimicrobial effect might be attributed to the disruption of the bacterial membrane. Because of the rather non-specific mechanism toward the bacterial membrane [39], magainin- $A$ is active against a broad spectrum of microbes. The same data provides convincing evidence that in vitro, magainin-A is effective against some of the STI-causing pathogens [39]. Some data demonstrated that magainins have antiviral properties, for example, magainins I and II exhibited inhibitory action toward Herpes Simplex Virus 1 and 2 (HSV-1 and HSV-2) at reduced and non-cytotoxic concentrations for epithelial cells (lower than $50 \mu \mathrm{g} / \mathrm{mL}$ ) [40]. They also showed significant reduction of HSV plaque-forming units. The antiviral effect was enhanced when HSV was pretreated with the peptides prior to inoculation onto Vero monolayers, suggesting a direct effect on the virion as it is shown by Egal et al. [41].

Apart from its antimicrobial activities, magainins have also been explored for their contraceptive effects. Reddy and co-workers [24] demonstrated the spermicidal activity of magainins-A, both in vitro and in vivo. The minimum concentration of magainin-A required to immobilize spermatozoa $\left(80 \times 10^{6}-80 \times 10^{8} / \mathrm{mL}\right)$ within 20 seconds under in vitro conditions was found to be $50 \mu \mathrm{g} / \mathrm{mL}$ in rat and $200 \mu \mathrm{g} / \mathrm{mL}$ in rabbits. However, in the case of monkeys the concentration required was five-fold higher compared to that of rabbits and the effect was found to be both time- and dosedependant. In vivo studies on rats indicated that when $200 \mu \mathrm{g}$ of magainin-A was applied intravaginally complete arrest of sperm mobility was observed and none of these treated animals conceived [24]. Reddy and Manjramkar [42] later evaluated the contraceptive effect of magainins-A in rabbits in vivo. These studies show that $1 \mathrm{mg}$ of magainin-A applied intravaginally once before mating resulted in complete arrest of sperm motility and none of the treated animals conceived. We no longer use rabbits for the evaluation of vaginal contraceptive potential of newer compounds, because sperm transport through the rabbit cervix might differ from that 
TABLE 2: Activity of antimicrobial peptides against sexually transmitted infection causing pathogens [14].

\begin{tabular}{lc}
\hline Peptide & Anti-STI/HIV activities \\
\hline Rabbit-defensin mcp-1/mcp-2 & Herpes simplex virus \\
Human-defensin-1, -2 and -3 & HIV \\
Human-defensin & T. pallidum \\
Rabbit-defensin NP-1 & C. trachomatis \\
Protegrin & C. trachomatis \\
& N. gonorrhoeae \\
Cathelicidins & T. pallidum \\
Cecropin (D2A21/D4E1) & C. trachomatis \\
Mellitin & HIV \\
Polyphemusin & HIV \\
\hline
\end{tabular}

through the cervix of a woman [43]. Because monkeys are the only animal with a reproductive tract similar to that of women, they are a suitable model for postcoital testing [43]. That's why, the contraceptive efficacy of magainin-A was evaluated in monkeys as an in vivo model by Aranha and associates. The results indicated that $1 \mathrm{mg}$ of magaininA was sufficient to arrest completely sperm motility: none of the monkeys became pregnant as they returned to cyclicity in the following month [39]. They have also reported that the repeated intravaginal administration of contraceptive doses of magainin-A caused no adverse effects on the morphology of vaginal epithelial cells or on hematologic and serum biochemical profiles [39]. The interesting observation of this study is the selective action of magainin-A on spermatozoa, RBCs, and vaginal cells.

\section{Dermaseptins S}

Dermaseptins $S$ are a family of eight closely related peptides that were originally isolated from the skin of a tree-dwelling, South American frog (Phyllomedusa sauvagei). These compounds are linear polycationic peptides, composed of 28-34 amino acids, which are structured in amphipathic-helices in apolar solvents [45]. They all have a conserved Trp residue at position 3, an $\mathrm{AG}(\mathrm{A}) \mathrm{KAAL}(\mathrm{V} / \mathrm{G}) \mathrm{G}(\mathrm{N} / \mathrm{K}) \mathrm{AV}(\mathrm{A})$ consensus motif in the mid21region and a positive charge attributable to the presence of Lys residues that punctuate an alternating hydrophobic and hydrophilic sequence $[45,46]$. Recently, the identification of new members of the dermaseptin $S$ family (S9-S11), different from the current antimicrobial peptides, has been reported after cloning from a skin secretion-derived cDNA library [47].

Some dermaseptins show a remarkable ability to inhibit microbial cells efficiently, rapidly and irreversibly without a toxic effect upon mammalian cells $[48,49]$. Dermaseptins and its analogs display cytolytic activity in vitro, generally against a broad spectrum of host-free microorganisms, including a series of multidrug-resistant Gram-negative clinical isolates [48], Gram-positive strains [49, 50], especially germs responsible of genital infections such as $N$. gonorrhoea [26]. In fact, antimicrobial-resistant gonococcal infection continues to be a serious public health problem worldwide. In recent data, Zairi et al. had described the anti-N. gonorrhoeae activity of 5 related synthetic peptides derived from the natural antimicrobial peptide dermaseptin S4 (Table 2). They showed that dermaseptin S4 and its analogs are effective against 9 reference and clinical $N$. gonorrhoeae strains, and that these effects are dose and time dependent. Among the different peptides tested, they found that dermaseptin K4-S4(1-16)a and dermaseptin K4S4(1-28) were the more potent to inhibit N. gonorrhoeae growth with MIC of $10 \mu \mathrm{g} / \mathrm{mL}$. They also showed that the inhibition of growth was dependent on the nature of the peptide, and the highly charged molecules were the most active. Dermaseptin K4-S4(1-28) showed the highest activity with an MIC of $10 \mu \mathrm{g} / \mathrm{mL}$ [25]. Generally, the data obtained from in vitro and in vivo experiments indicate that some dermaseptin $\mathrm{S}$ derivatives could be very useful in a variety of antimicrobial applications [51], especially against opportunistic fungal infections such as Candida, which is the most commonly encountered fungal pathogen in the human vagina [52]. Besides Candida, other fungal infections can also adversely affect female reproductive health. A. fumigatus spores introduced through the vagina cause abortion in pregnant animals [53]. In view of this consideration, Zairi et al. had evaluated dermaseptins S4 and its analogs for their fungicidal activity. They showed that dermaseptin S4 and its analogs are effective against clinical C. albicans strains, with a dose-dependent manner; and the most potent one is the dermaseptin K4S4(1-28) which had a potent fungicidal activity at $6 \mu \mathrm{g} / \mathrm{mL}$ [26]. Dermaseptins $\mathrm{S}$ are also effective against protozoa (Leishmania mexicana and Plasmodium falciparum) [51, 54-56], yeasts as well as filamentous fungi (Aspergillus fumigatus and Aspergillus niger) $[46,57]$. Recently, Lorin et al. have evaluated the anti- HIV activity of one analog of dermaseptin K4S4(1-28) on HeLa P4-CCR5 cells as well as on primary PBMCs and have observed that this analog had reduced cell toxicity at high concentrations (CC50 = $16,8 \mu \mathrm{M})$ [58]. In addition, they have also demonstrated that dermaseptin K4S4(1-28) could be a potential anti-HIV candidate able to disrupt viral particles before infection [58]. The same data had also showed that this peptide reduces HIV-1 attachment to human endometrial cells (HEC-1) and HIV-1 transcytosis through a tight HEC-1 monolayer. Moreover, dermaseptin K4S4 presented an improved toxicity profile, although human endometrial epithelial cells are less sensitive to the toxic effect of dermaseptins than other cells [58]. This is an important point because these cells would be the major cell population in contact with a topical microbicide. Thus, these molecules need to be evaluated as new candidates with additional protection against STDs. In addition to their antimicrobial activities, dermaseptins and its analogs have also been explored for their contraceptive effects. Zairi and coworkers [44] elucidated the spermicidal efficacy of two dermaseptins S1 and S4, both in vitro. The minimum concentration of DS4 required to immobilize spermatozoa $\left(80 \times 10^{6}-80 \times 10^{8} / \mathrm{mL}\right)$ within 20 seconds under in vitro conditions was found to be $100 \mu \mathrm{g} / \mathrm{mL}$ on human spermatozoa. The same data showed that sperm motility was inhibited with various concentrations of $\mathrm{S}$ at different intervals ranging from 5 to 240 minutes. 


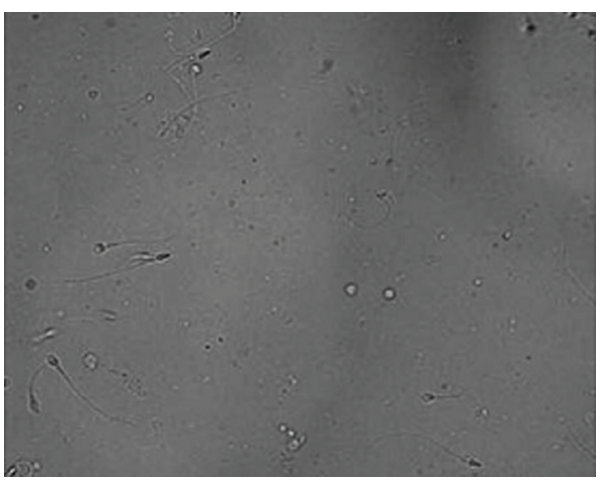

(a)

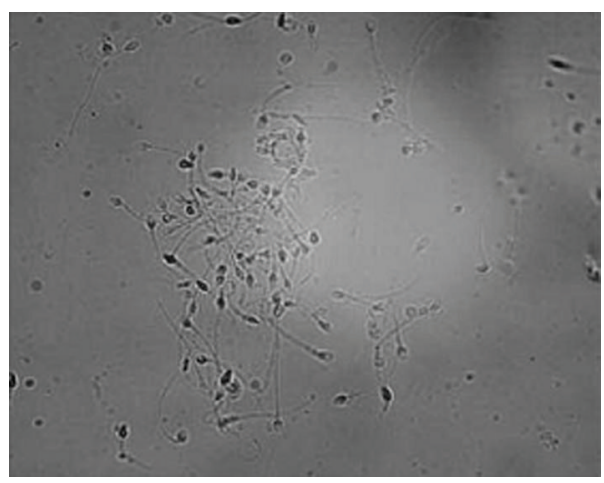

(b)

Figure 1: Effect of dermaseptin on sperm motility. Motile spermatozoa were preincubated in the presence or absence of increasing concentrations of five dermaseptins derivatives for 20 seconds photomicrographics (a) control and (b) in the presence of dermaseptin; complete sperm immobilization was seen after treatment (aggregate of spermatozoa at $\mathrm{EC}_{100}=25 \mu \mathrm{g} / \mathrm{mL}$ )). Original magnification 100 [44].

The effective $100 \%$ inhibitory concentration (EC100) of S4 in 2 minutes during the sperm immobilization assay was $100 \mu \mathrm{g} / \mathrm{mL}$ whereas the sperm immobilization of EC100 of S1 was $200 \mu \mathrm{g} / \mathrm{mL}$. The presence of $0.1 \%$ chelating agent ethylenediaminetetraacetic acid (EDTA) reduced the EC100 of $S 4$ to $10 \mu \mathrm{g} / \mathrm{mL}$ whereas less than a two-time enhancement in S1 activity was observed upon combination with EDTA. The striking phenomenon of synergistic enhancement with EDTA, suggests that $S$ probably affects the motility of sperm membrane by depleting cytosolic potassium and sodium whereas EDTA chelates extracellular calcium [27]. The action of DSs on sperm motility was observed to be dose dependent. Supplementation with pentoxifylline which is known to enhance the motility of sperm and that with calcium, a select sperm viability parameter did not prevent the spermicidal action of dermaseptins [27]. Recently, Zairi et al. have been used normal human semen samples to detect the spermicidal activity of new compounds of dermaseptins (Figure 1) [44]. In this study, HeLa cultures were used to determine the safety of compounds toward their toxicity. The data show that all DS4 derivatives elicited concentration-dependent spermicidal activity at microgram concentrations (EC100 values: $25 \mu \mathrm{g} / \mathrm{mL}-1 \mathrm{mg} / \mathrm{mL}$ ). In cytotoxicity assay, some compounds were found to be significantly safer than nonoxynol-9, the most widely used spermicide, and their activity was not accompanied by total loss of plasma membrane integrity as detected by fluorescent microscopy [27]. Fluorescentbinding assays were also performed to evaluate the rapidity and the irreversibility of the sperm-immobilizing activity of peptides. A double staining of the acrosome (with FITCPSA) and flagellum (with anti-tubulin) of spermatozoa incubated in the presence of non-fluorescent K4S4 also revealed a loss of the flagellar membrane integrity whereas the matrix and membrane of the acrosome remained intact as attested by the FITC-PSA staining on sperm head (Figure 2). By contrast, previous studies have demonstrated that sperm exposed to $100 \mu \mathrm{M}$ of nonoxynol-9 for 3 hours under identical conditions revealed complete loss of acrosomal staining with FITC-lectin. The study also shows that increasing the number of positive charges of the peptide resulted in a reduced cytotoxicity without affecting the spermicidal effects [44]. A major problem faced by the microbicides is the $\mathrm{pH}$ of the vaginal tissues in which they have to act. It is known that the vaginal $\mathrm{pH}$ is around 4 and that $\mathrm{pH}$ rises to 8 after deposition of semen. Interestingly, Mor and associates have shown in a recent study that Dermaseptins $S$ remained active in extreme conditions of incubation such as variation of $\mathrm{pH}$. This is important for the microbicide future of such compounds because they would retain their activity over a range of $\mathrm{pH}$ values [59].

\section{Conclusion}

Sexually transmitted diseases pathogens are a growing problem now and pose a serious public health threat. To overcome the infections caused by multidrug-resistant strains and strains resistant to all available antimicrobials, new classes of antimicrobials should be developed. This has been recognized by the US congress Office of Technology Assessment and by the United Kingdom House of Lords [25]. In addition to this burden, there has been a tremendous increase in the number of unintended pregnancies. Prophylactic contraception is fundamentally important especially in HIV-infected women for prevention of HIV transmission and pregnancy. Antimicrobial peptides represent a promising class of new agents. These agents are rapidly bactericidal, and because their action relates to physical properties, it is all the more difficult for bacteria to develop resistance to such peptides. Moreover, it is possible to engineer their structure with relative ease, because peptide chemistry allows a multitude of modifications that are relatively time- and costeffective. However although various topical applications are considered, antimicrobial peptide notoriously lack adequate specificity, while their relative toxicity toward red blood cells limits their potential systemic use. Another significant and prohibitive factor is their relatively high cost, at least as long as they are produced by chemical synthesis. Thus new strategies are needed to reduce toxicity and coast [60-62]. 


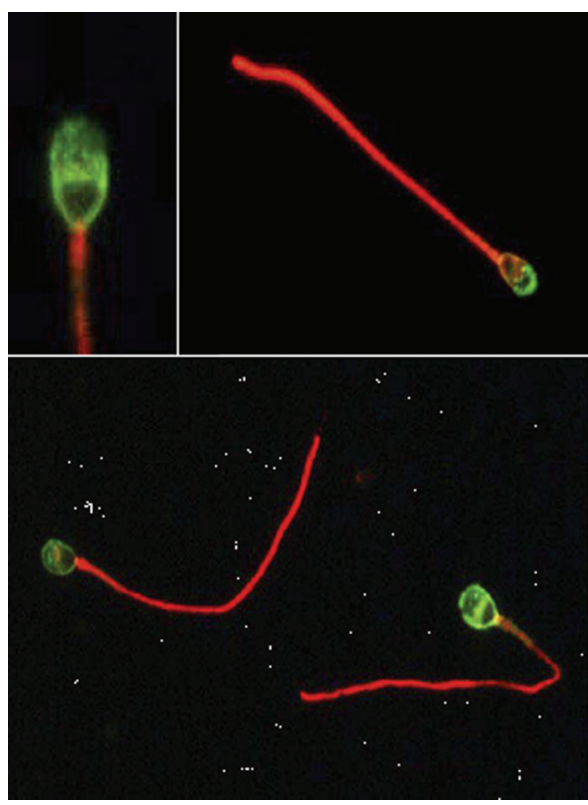

Figure 2: Effect of spermicidal dermaseptins on sperm acrosome and flagellar plasma membrane integrity. Motile sperm were preincubated in the presence of spermicide solution $(\mathrm{EC} 100=$ $25 \mu \mathrm{g} / \mathrm{mL}$ ) of K4S4 and was double labelled with Fluorescein Isothiocyanate-conjugated-Pisum sativum Agglutinin for acrosome labelling (FITC/green) and mouse antitubulin antibody for the flagellum staining (CY3/red). The sperm heads exhibited a "dotted" green fluorescence attesting for the presence of an acrosome. At the flagellar level, we observed a loss of membrane integrity since the anti tubulin antibodies have reached their axonemal microtubule target [44].

Several AMPs are currently undergoing laboratory testing but few have already reached clinical trials. For instance P-113, a derivative of histatin, a human salivary peptide, is undergoing phase I/II trials to treat oral candidiasis affecting immunocompromised patients [63]. Pexiganan, derived from magainin, is being developed for treatment of infected foot ulcers in diabetics [63]. The study is undergoing Phase III clinical trials.

In spite of all the positive facts associate with AMPs, there have been a few problems. Firstly, there are fewer data available on the unknown in vitro/in vivo toxicities of the peptide [64]. Secondly, the stability of the peptide/peptide formulations in vivo has not been studied in detail. And lastly the cost of production of these peptides on a large scale has been a major obstacle for quite some time. Subsequently, these issues have been sorted out one by one. The problem of stability has been removed by using the peptide formulations in combination with a protease inhibit or by modifying the amino acid composition enabling them to be recognized by the proteases. The problem of large scale production has been taken care by the growing advent of recombinant synthesis technology which is effective and cheaper [14].

It is clear from the above observations that Dermaseptins and Magainins are potential candidates for microbicides. Studies have clearly shown the in vitro efficacy of these peptides against a lot of STI-causing pathogens. Antimicrobial activity against more recent isolates should be evaluated for both peptides. As well, their activity should be evaluated against other STDs agents, such as HSV-2, Trichomonas vaginalis, Treponema pallidum, Chlamydia trachomatis, Gardnerella, Mobiluncus, Mycoplasma, Ureaplasma and others. Dermaseptins S and magainins may have the potential for being used as safe and effective microbicide spermicide compounds. Further studies in this direction are underway to establish in animal models the efficacy and the safety of these peptides alone or in combination with other potential compounds.

\section{References}

[1] O. J. D'Cruz and F. M. Uckun, "Clinical development of microbicides for the prevention of HIV infection," Current Pharmaceutical Design, vol. 10, no. 30, pp. 315-336, 2004.

[2] I. M. Poynten, I. Y. Millwood, M. O. Falster, et al., "The safety of candidate vaginal microbicides since nonoxynol-9: a systematic review of published studies," AIDS, vol. 23, no. 10, pp. 1245-1254, 2009.

[3] CDCP update, "US HIV and AIDS cases reported through December 1996," HIV/AIDS Surveillance Report 8; 1-33, 1997.

[4] J. Weber, A. Nunn, and O. Connor, "Chemical condoms for the prevention of HIV infection: evaluation of novel agents against SHIV (89.6 pd) in vitro and in vivo," AIDS, vol. 15, no. 18, pp. 1563-1568, 2001.

[5] L. J. D. Zaneveld, R. A. Anderson, X.-H. Diao, et al., "Use of mandelic acid condensation polymer (SAMMA), a new antimicrobial contraceptive agent, for vaginal prophylaxis," Fertility and Sterility, vol. 78, no. 5, pp. 1107-1115, 2002.

[6] O. J. D'Cruz, T. K. Venkatachalam, and F. M. Uckun, "Structural requirements for potent human spermicidal activity of dual- function aryl phosphate derivative of bromo-methoxy zidovudine (compound WHI- 07)," Biology of Reproduction, vol. 62, no. 1, pp. 37-44, 2000.

[7] S. L. Hillier, T. Moench, R. Shattock, R. Black, P. Reichelderfer, and F. Veronese, "In vitro and in vivo: the story of nonoxynol 9," Journal of Acquired Immuno Deficiency Syndromes, vol. 39, no. 1, pp. 1-8, 2005.

[8] F. M. Uckun and O. J. D’Cruz, "Prophylactic contraceptives for HIV/AIDS," Human Reproduction Update, vol. 5, no. 5, pp. 506-514, 1999.

[9] R. E. Roddy, L. Zekeng, K. A. Ryan, U. Tamoufé, and K. G. Tweedy, "Effect of nonoxynol-9 gel on urogenital gonorrhea and chlamydial infection: a randomized controlled trial," Journal of the American Medical Association, vol. 287, no. 9, pp. 1117-1122, 2002.

[10] O. J. D'Cruz and F. M. Uckun, "Gel-microemulsions as vaginal spermicides and intravaginal drug delivery vehicles," Contraception, vol. 64, no. 2, pp. 113-123, 2001.

[11] F. C. Krebs, S. R. Miller, B. J. Catalone, et al., "Sodium dodecyl sulfate and $\mathrm{C} 31 \mathrm{G}$ as microbicidal alternatives to nonoxynol 9: comparative sensitivity of primary human vaginal keratinocytes," Antimicrobial Agents and Chemotherapy, vol. 44, no. 7, pp. 1954-1960, 2000.

[12] I. J. Rosenstein, M. K. Stafford, V. S. Kitchen, H. Ward, J. N. Weber, and D. Taylor-Robinson, "Effect on normal vaginal flora of three intravaginal microbicidal agents potentially active against human immunodeficiency virus type 1," Journal of Infectious Diseases, vol. 177, no. 5, pp. 1386-1390, 1998. 
[13] M. K. Stafford, H. Ward, A. Flanagan, et al., "Safety study of nonoxynol-9 as a vaginal microbicide: evidence of adverse effects," Journal of Acquired Immuno Deficiency Syndromes and Human Retrovirology, vol. 17, no. 4, pp. 327-331, 1998.

[14] K. V. R. Reddy, R. D. Yedery, and C. Aranha, "Antimicrobial peptides: premises and promises," International Journal of Antimicrobial Agents, vol. 24, no. 6, pp. 536-547, 2004.

[15] D. Hultmark, "Drosophila immunity: paths and patterns," Current Opinion in Immunology, vol. 15, no. 1, pp. 12-19, 2003.

[16] R. Bals, "Epithelial antimicrobial peptides in host defense against infection," Respiratory research, vol. 1, no. 3, pp. 141$150,2000$.

[17] K. L. Brown and R. E. Hancock, "Cationic host defense (antimicrobial) peptides," Current Opinion in Immunology, vol. 18, no. 1, pp. 24-30, 2006.

[18] L. Zhang, W. Yu, T. He, et al., "Contribution of human $\alpha$ defensin 1, 2, and 3 to the anti-HIV-1 activity of CD8 antiviral factor," Science, vol. 298, no. 5595, pp. 995-1000, 2002.

[19] X. Qu, S. L. Harwig, and A. Oren, "Susceptibilty of Neisseria gonorrhoeae to protegrins," Infection and Immunity, vol. 65, pp. 636-639, 1996.

[20] B. Yasin, S. L. Harwig, R. I. Lehrer, and E. A. Wagar, "Susceptibility of Chlamydia trachomatis to protegrins and defensins," Infection and Immunity, vol. 64, no. 3, pp. 709-713, 1996.

[21] K. E. Sutyak, R. A. Anderson, S. E. Dover, et al., "Spermicidal activity of the safe natural antimicrobial peptide subtilosin," Infectious Diseases in Obstetrics and Gynecology, vol. 2008, pp. $1-6,2008$

[22] C. Aranha, S. Gupta, and K. V. R. Reddy, "Contraceptive efficacy of antimicrobial peptide Nisin: in vitro and in vivo studies," Contraception, vol. 69, no. 4, pp. 333-338, 2004.

[23] M. Zasloff, B. Martin, and H.-C. Chen, "Antimicrobial activity of synthetic magainin peptides and several analogues," Proceedings of the National Academy of Sciences of the United States of America, vol. 85, no. 3, pp. 910-913, 1988.

[24] K. V. R. Reddy, S. K. Shahani, and P. K. Meherji, "Spermicidal activity of magainins: in vitro and in vivo studies," Contraception, vol. 53, no. 4, pp. 205-210, 1996.

[25] A. Zairi, F. Tangy, M. Ducos-Galand, J.-M. Alonso, and K. Hani, "Susceptibility of Neisseria gonorrhoeae to antimicrobial peptides from amphibian skin, dermaseptin, and derivatives," Diagnostic Microbiology and Infectious Disease, vol. 57, no. 3, pp. 319-324, 2007.

[26] A. Zairi, F. Tangy, S. Saadi, and K. Hani, "In vitro activity of dermaseptin S4 derivatives against genital infections pathogens," Regulatory Toxicology and Pharmacology, vol. 50, no. 3, pp. 353-358, 2008.

[27] A. Zairi, A. Belaïd, A. Gahbiche, and K. Hani, "Spermicidal activity of dermaseptins," Contraception, vol. 72, no. 6, pp. 447-453, 2005.

[28] L. H. Caporale, "Chance favors the prepared genome," Annals of the New York Academy of Sciences, vol. 870, pp. 1-21, 1999.

[29] C. Severini, G. Importa, V. Falconieri-Erspamer, S. Salvadori, and V. Erspamer, "The tachykinin peptide family," Pharmacological Reviews, vol. 54, pp. 285-322, 2002.

[30] M. Simmaco, G. Mignogna, and D. Barra, "Antimicrobial peptides from amphiban skin: what they tell us?" Biopolymers, vol. 47, pp. 435-450, 1998.

[31] C. Lacombe, C. Cifuentes-Diaz, I. Dunia, M. Auber-Thomay, P. Nicolas, and M. Amiche, "Peptide secretion in the cutaneous glands of South American tree frog Phyllomedusa bicolor: an ultrastructural study," European Journal of Cell Biology, vol. 79, no. 9, pp. 631-641, 2000.

[32] L. Jacob and M. Zasloff, "Potential therapeutic applications of magainins and other antimicrobial agents of animal origin," Ciba Foundation Symposium, vol. 186, pp. 197-223, 1994.

[33] M. Zasloff, "Antimicrobial peptides in health and disease," The New England Journal of Medicine, vol. 347, pp. 1151-1160, 2002.

[34] W. E. Dulleman and L. Trueb, Biology of Amphibians, John Hopkins University Press, London, UK, 25th edition, 1994.

[35] S. E. van Compernolle, R. J. Taylor, K. Oswald-Richter, et al., "Antimicrobial peptides from amphibian skin potently inhibit human immunodeficiency virus infection and transfer of virus from dendritic cells to T cells," Journal of Virology, vol. 79, no. 18, pp. 11598-11606, 2005.

[36] M. G. Giovannini, L. Poulter, B. W. Gibson, and D. H. Williams, "Biosynthesis and degradation of peptides derived from Xenopus laevis prohormones," Biochemical Journal, vol. 243, no. 1, pp. 113-120, 1987.

[37] M. Zasloff, "Magainins, a class of antimicrobial peptides from Xenopus skin: isolation, characterization of two active forms, and partial cDNA sequence of a precursor," Proceedings of the National Academy of Sciences of the United States of America, vol. 84, no. 15, pp. 5449-5453, 1987.

[38] K. P. Sai, P. N. Reddy, and M. Babu, "Investigations on wound healing by using amphibian skin," Indian Journal of Experimental Biology, vol. 33, no. 9, pp. 673-676, 1995.

[39] A. Clara, D. D. Manjramkar, and V. K. Reddy, "Preclinical evaluation of magainin-A as a contraceptive antimicrobial agent," Fertility and Sterility, vol. 81, no. 5, pp. 1357-1365, 2004.

[40] V. C. Albiol Matanic and V. Castilla, "Antiviral activity of antimicrobial cationic peptides against Junin virus and herpes simplex virus," International Journal of Antimicrobial Agents, vol. 23, no. 4, pp. 382-389, 2004.

[41] M. Egal, M. Conrad, D. L. MacDonald, W. L. Maloy, M. Motley, and C. A. Genco, "Antiviral effects of synthetic membrane-active peptides on herpes simplex virus, type 1," International Journal of Antimicrobial Agents, vol. 13, no. 1, pp. 57-60, 1999.

[42] V. R. K. Reddy and D. D. Manjramkar, "Evaluation of the antifertility effect of magainin-A in rabbits: in vitro and in vivo studies," Fertility and Sterility, vol. 73, no. 2, pp. 353-358, 2000.

[43] B. Zatuchni, D. W. Hahn, and L. J. D. Zaneveld, "Postcoital, vaginal, spermicidal potency of formulations: the Macaca arctoides (stumptailed macaque) as animal model," Fertility and Sterility, vol. 35, no. 6, pp. 683-690, 1981.

[44] A. Zairi, C. Serres, F. Tangy, P. Jouannet, and K. Hani, "In vitro spermicidal activity of peptides from amphibian skin: dermaseptin S4 and derivatives," Bioorganic \& Medicinal Chemistry, vol. 16, no. 1, pp. 266-275, 2008.

[45] A. Mor and P. Nicolas, "Isolation and structure of novel defensive peptides from frog skin," European Journal of Biochemistry, vol. 219, no. 1-2, pp. 145-154, 1994.

[46] A. Mor, K. Hani, and P. Nicolas, "The vertebrate peptide antibiotics dermaseptins have overlapping structural features but target specific microorganisms," The Journal of Biological Chemistry, vol. 269, no. 50, pp. 31635-31641, 1994.

[47] O. Lequin, A. Ladram, L. Chabbert, et al., "Dermaseptin S9, an $\alpha$-helical antimicrobial peptide with a hydrophobic core and cationic termini," Biochemistry, vol. 45, no. 2, pp. 468-480, 2006 
[48] S. Navon-Venezia, R. Feder, L. Gaidukov, Y. Carmeli, and A. Mor, "Antibacterial properties of dermaseptin S4 derivatives with in vivo activity," Antimicrobial Agents and Chemotherapy, vol. 46, no. 3, pp. 689-694, 2002.

[49] I. Kustanovich, D. E. Shalev, M. Mikhlin, L. Gaidukov, and A. Mor, "Structural requirements for potent versus selective cytotoxicity for antimicrobial dermaseptin $\mathrm{S} 4$ derivatives," The Journal of Biological Chemistry, vol. 277, no. 19, pp. 1694116951, 2002.

[50] R. Feder, A. Dagan, and A. Mor, "Structure-activity relationship study of antimicrobial dermaseptin S4 showing the consequences of peptide oligomerisation on selective cytotoxicity," The Journal of Biological Chemistry, vol. 275, pp. 4230-4238, 2000.

[51] M. Krugliak, R. Feder, V. Y. Zolotarev, et al., "Antimalarial activities of dermaseptin S4 derivatives," Antimicrobial Agents and Chemotherapy, vol. 44, no. 9, pp. 2442-2451, 2000.

[52] J. R. Naglik, S. J. Challacombe, and B. Hube, "Candida albicans secreted aspartyl proteinases in virulence and pathogenesis," Microbiology and Molecular Biology Reviews, vol. 67, no. 3, pp. 400-428, 2003.

[53] S. Venev, "Experimental abortions in mice and guinea pigs caused by Aspergillus fumigatus spores," VeterinarnoMeditsinski Nauki, vol. 13, no. 1, pp. 86-93, 1976.

[54] C. Hernandez, A. Mor, F. Dagger, et al., "Functional and structural damage in Leishmania mexicana exposed to the cationic peptide dermaseptin," European Journal of Cell Biology, vol. 59, no. 2, pp. 414-424, 1992.

[55] A. Dagan, L. Efron, L. Gaidukov, A. Mor, and H. Ginsburg, "In vitro antiplasmodium effects of dermaseptins," Antimicrob Agents Chemother, vol. 46, pp. 1059-1066, 2002.

[56] L. Efron, A. Dagan, L. Gaidukov, H. Ginsburg, and A. Mor, "Direct interaction of dermaseptin S4 aminoheptanoyl derivate with intra-erythrocytic malaria parasite leading to increased specific antiparasitic activity in culture," The Journal of Biological Chemistry, vol. 277, pp. 24067-24072, 2002.

[57] P. J. Coote, C. D. Holyoak, D. Bracey, D. P. Ferdinando, and J. A. Pearce, "Inhibitory action of a truncated derivative of the amphibian skin peptide dermaseptin s3 on Saccharomyces cerevisiae," Antimicrobial Agents and Chemotherapy, vol. 42, no. 9, pp. 2160-2170, 1998.

[58] C. Lorin, H. Saidi, A. Belaid, A. Zairi, F. Baleux, and H. Hocini, "The antimicrobial peptide dermaseptin S4 inhibits HIV-1 infectivity in vitro," Virology, vol. 334, no. 2, pp. 264-275, 2005.

[59] T. Rydlo, S. Sotem, and A. Mor, "Antibacterial 1 properties of dermaseptin S4 derivatives under extreme incubation conditions," Antimicrobial Agents and Chemotherapy, vol. 50, no. 2, pp. 490-507, 2006.

[60] E. Andres and J. L. Dimarq, "Clinical development of antimicrobial peptides," The International Journal of Antimicrobial Agents, vol. 25, pp. 448-449, 2005.

[61] O. Levy, "Antimicrobial proteins and peptides of blood: templates for novel antimicrobial agents," Blood, vol. 96, no. 8, pp. 2664-2672, 2000.

[62] T. Gura, "Innate immunity: ancient system gets new respect," Science, vol. 291, no. 5511, pp. 2068-2071, 2001.

[63] D. W. Paquette, D. M. Simpson, P. Friden, V. Braman, and R. C. Williams, "Safety and clinical effects of topical histatin gels in humans with experimental gingivitis," Journal of Clinical Periodontology, vol. 29, no. 12, pp. 1051-1058, 2002.

[64] R. E. W. Hancock, "Host defence (cationic) peptides. What is their future clinical potential?” Drugs, vol. 57, pp. 469-473, 1999. 

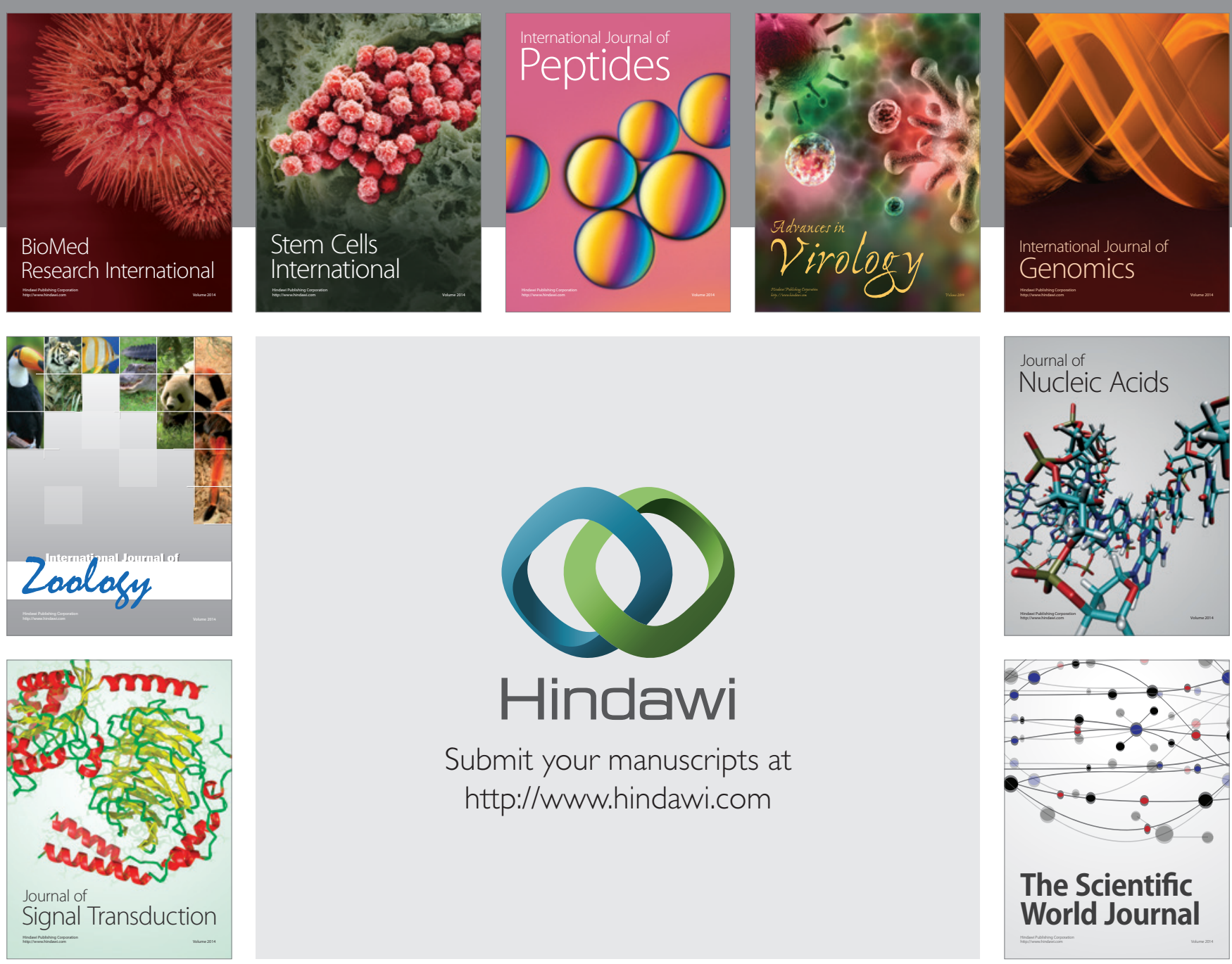

Submit your manuscripts at

http://www.hindawi.com
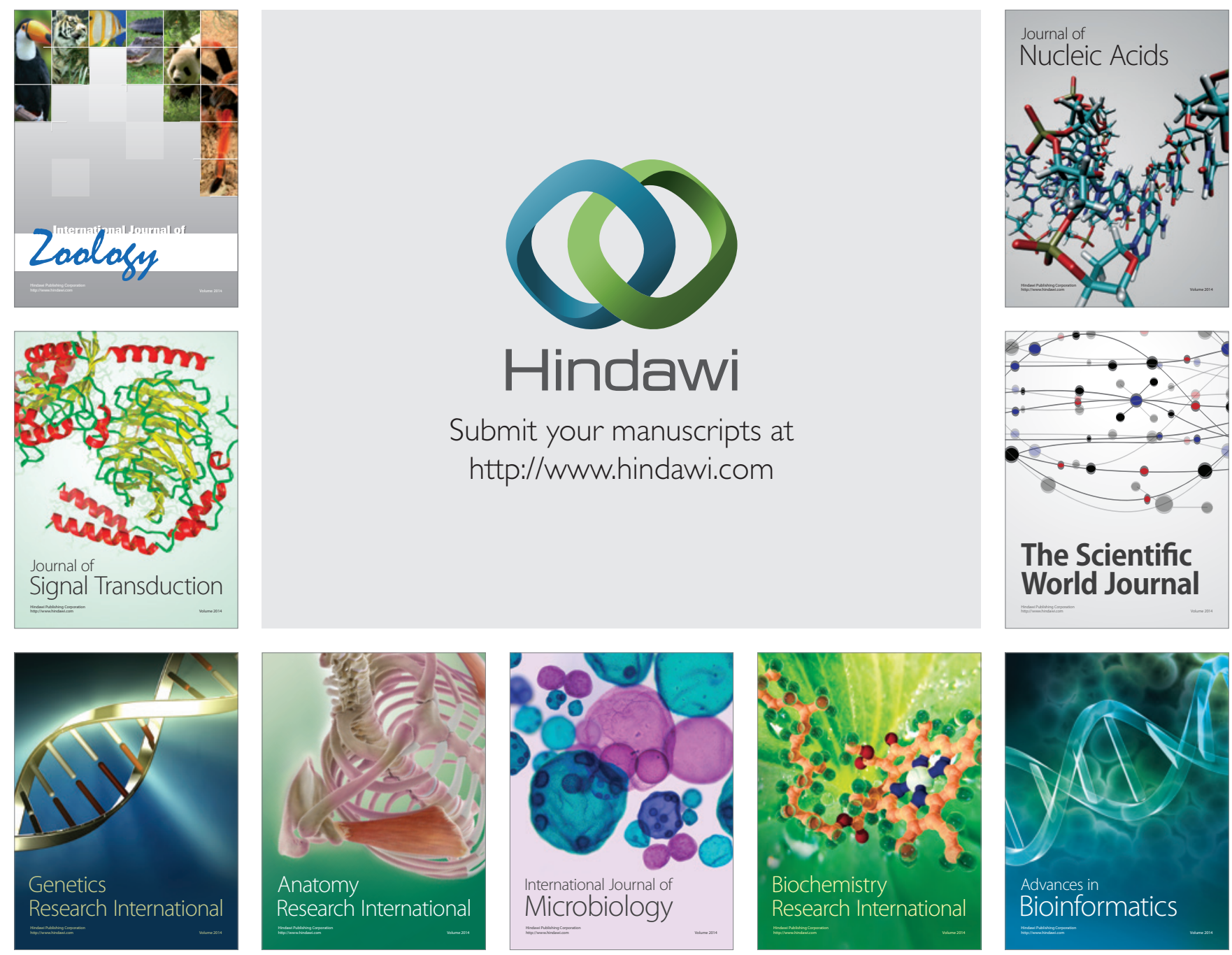

The Scientific World Journal
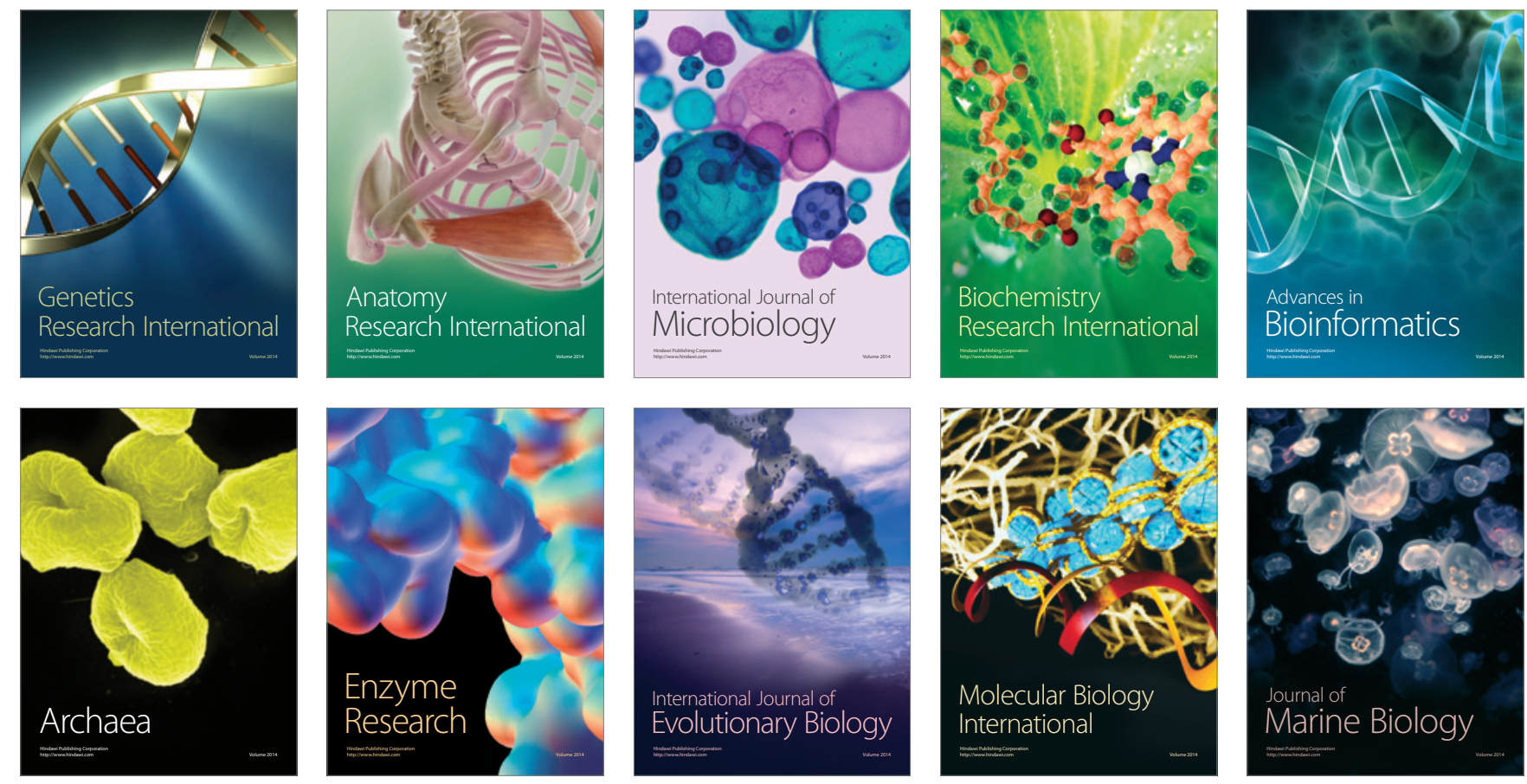